\title{
Neuron-Specific Enolase: A Neuronal Survival Factor in the Retinal Extracellular Matrix?
}

\author{
Anren Li, ${ }^{1}$ William S. Lane, ${ }^{2}$ Lincoln V. Johnson, ${ }^{3}$ Gerald J. Chader, ${ }^{1}$ and Joyce Tombran-Tink ${ }^{1}$ \\ 1 Laboratory of Retinal Cell and Molecular Biology, National Eye Institute, National Institutes of Health, Bethesda, Maryland \\ 20892, ${ }^{2}$ Harvard Microchemistry Facility, Harvard University, Cambridge, Massachusctts 02138, and ${ }^{3}$ Department of \\ Anatomy and Cell Biology, USC School of Medicine, Los Angeles, California 90033
}

\begin{abstract}
To identify soluble proteins of the retinal interphotoreceptor matrlx (IPM), we isolated IPM from the bovine eye by gentle lavage and subjected it to SDS-PAGE. In the resultant gel, a $46 \mathrm{kDa}$ band was particularly prominent and appeared to be a single protein. This protein was electroblotted to nitrocellulose membrane, digested with trypsin, and selected peptides were isolated by HPLC and subjected to Edman microsequencing. The amino acid sequences of the peptides were found to be virtually identical to that of human neuron-specific enolase (NSE). A monoclonal antibody specific for human NSE confirmed the presence of this enzyme in the bovine IPM by both Western blotting and immunocytochemical analysis. Immunofluorescence microscopy demonstrated that NSE is mainly localized to the basal domain of the IPM surrounding photoreceptor cells but is also prominent in the inner segments of the cone photoreceptor neurons. When NSE was added to cultures of human retinoblastoma cells, no effect on morphology was observed. However, a positive effect on cell growth and/or survival was readily apparent. It thus seems that not only is NSE a significant component of the retinal extracellular matrix, but that it could function as a survival (neuronotrophic) factor for photoreceptor neurons.
\end{abstract}

IKey words: neuron-specific enolase, retina, neuron survival factor, interphotoreceptor matrix, extracellular matrlx, photoreceptor, neuron, neuronotrophic protein]

Although extracellular matrix components have been well characterized in some tissues (Martin and Timpl, 1987), relatively little is known about such matrices in the CNS. The retinal interphotoreceptor matrix (IPM) is a specialized extracellular matrix lying between the retinal pigment epithelium (RPE) and the neural retina. Any exchange of nutrients, metabolites, or Irophic factors between the RPE and neural retina must traverse the IPM. This intermediary position thus allows the IPM to play a central role in mediating the developmental and physiological interactions between the neural retina and the RPE in the embryo and in the adult. Thus, the IPM is considered to be an integral part of a neural retina-RPE functional complex (Hageman and Johnson, 1991). The IPM contains a complex

Received Feb. 25, 1994; revised June 20, 1994; accepted June 22, 1994.

We thank Renee Robinson and Mary Gordy for their expert technical assistance. Correspondence should be addressed to Dr. Joyce Tombran-Tink, Building 6 , Room 311, National Eye Institute, National Institutes of Health, Bethesda, MD 20892.

Copyright (C) 1995 Society for Neuroscience $0270-6474 / 95 / 150385-09 \$ 05.00 / 0$ array of proteins and glycoproteins (Adler and Klucznik, 1982). Although most of these are products of the neural retina (photoreceptor neurons and Muller glial cells) and RPE, few have yet been identified. We have previously shown that soluble fractions of adult bovine IPM contain a neurotrophic factor(s) that induces neuronal differentiation in Y-79 retinoblastoma cells (Tombran-Tink et al., 1992). Similar neurotrophic activity is associated with a specific pigment epithelium-derived factor (PEDF), a protein of approximately $50 \mathrm{kDa}$ that is secreted by cultured fetal human RPE cells (Tombran-Tink and Johnson, 1989; Tombran-Tink et al., 1991). In an attempt to identify the molecule(s) containing neurotrophic activity in the IPM, we isolated a $45-50 \mathrm{kDa}$ protein from the bovine IPM to examine its possible sequence homology with PEDF. Surprisingly, we found almost complete homology of peptide fragments of this protein with the reported sequence of neuron-specific enolase (NSE). NSE is a well known neuronal marker enzyme of about the same size as PEDF, but it is a biochemically distinct protein. In the present study, we describe the localization of NSE in the IPM and also propose a functional role for this protein as a neuronal survival (neuronotrophic) factor.

\section{Materials and Methods}

\section{Tissue preparation}

The anterior segment, vitreous, and neural retina of adult human (obtained from the Clinical Branch, NEI) or bovine (obtained from Trueth and Sons, Baltimore, MD) eyes were removed. The resultant eye cups were gently rinsed with $0.5 \mathrm{ml}$ of $0.1 \mathrm{M}$ phosphate-buffered saline (PBS, $\mathrm{pH}$ 7.4) solution. The resultant soluble IPM preparation was centrifuged (three times at $1,000 \times \mathrm{g}, 10 \mathrm{~min}$ each), filtered, sterilized, and stored at $-20^{\circ} \mathrm{C}$ as previously described (Tombran-Tink et al., 1992). To prepare the soluble fraction of the retina, bovine retinas were homogenized in PBS and centrifuged three times for $10 \mathrm{~min}$ each at approximately $10,000 \times g$ to remove cellular debris.

Preparations of aqueous-insoluble bovine interphotoreceptor matrix were isolated as described previously (Johnson and Hageman, 1991). Briefly, retinas dissected from fresh bovine eyes were rinsed extensively with cold $10 \mathrm{~mm}$ phosphate-buffered saline (PBS) solution to remove soluble IPM components and then rocked gently in cold distilled water containing $2 \mathrm{mM} \mathrm{CaCl}_{2}$. During this period, sheets of insoluble IPM, including photoreceptor matrix sheaths and a small amount of photoreceptor cell outer segments, delaminated from the retina. These sheets are referred to as "aqueous-insoluble IPM" since they are not soluble in water but their detachment from the surface of the retina is induced by incubation in the calcium-containing solution. The sheets were collected by gentle, low-speed centrifugation, rinsed with $2 \mathrm{mM} \mathrm{CaCl} 2$ in water, and either (1) fixed in 4\% paraformaldehyde for immunofluorescence studies with peanut lectin (PNA) and neuron-specific enolase (NSE) antibody or (2) solubilized in electrophoresis sample buffer prior to SDS-PAGE and Western blotting. 


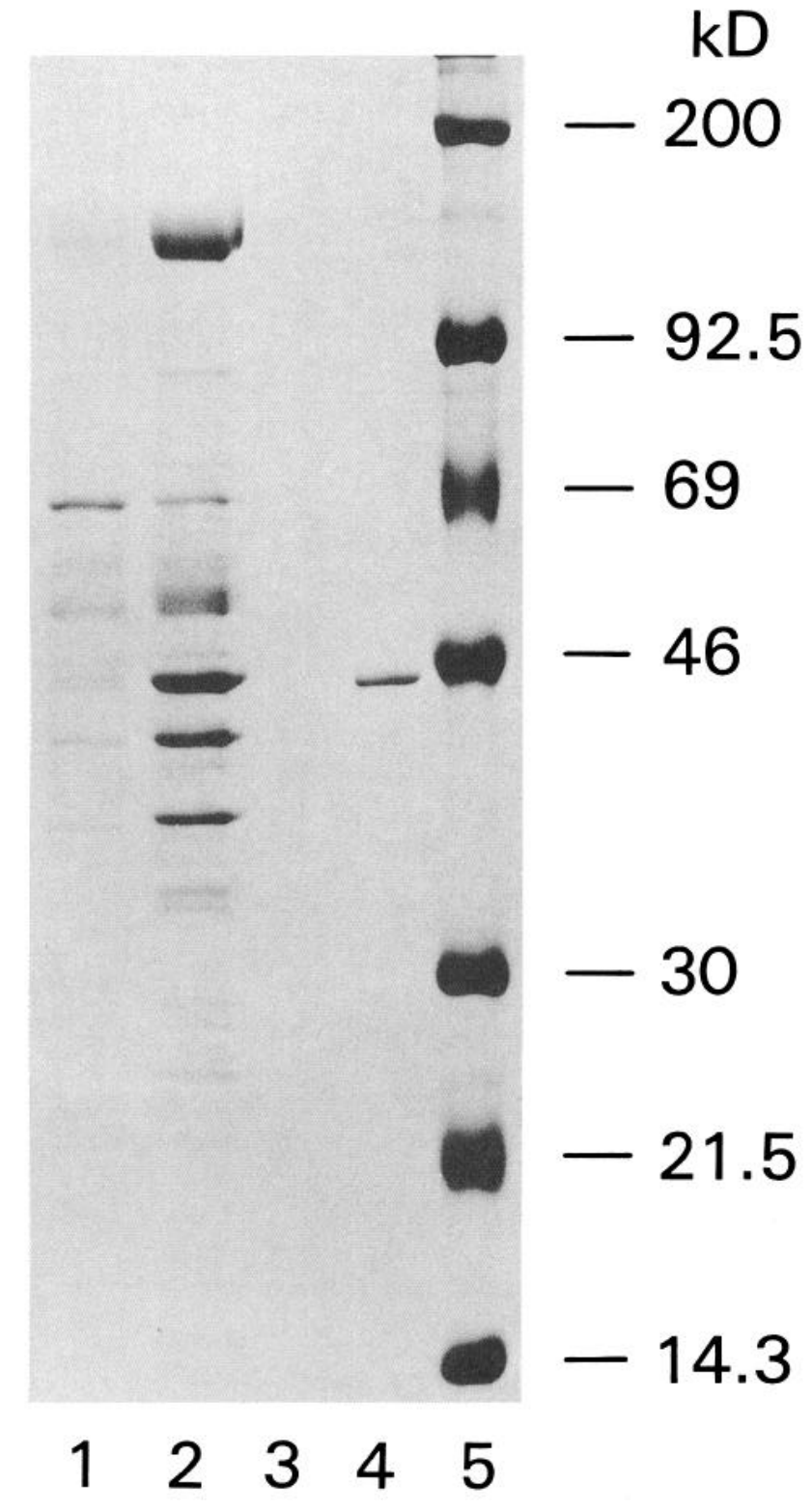

Figure 1. Coomassie blue-stained SDS-PAGE profiles of soluble IPM proteins. Lane 1, Adult human IPM. Lane 2, Adult bovine IPM. Lane 3, Blank. Lane 4, Purified human NSE. Lane 5, Molecular weight standards. Forty-six kilodalton bands are apparent in all samples.

\section{SDS-PAGE and Western blot analyses}

Purified human NSE was purchased from Polysciences, Inc. (Warrington, PA). Appropriate concentrations of NSE and aqueous-soluble and -insoluble fractions of IPM were separated on a $10 \%$ SDS-polyacrylamide gel or a 3-15\% precast SDS-gradient polyacrylamide gel (Jules, Inc., New Haven, CT). The proteins were transblotted onto nitrocellulose membrane for $1 \mathrm{hr}$ in Tris-borate buffer as previously described (Johnson and Hageman, 1991). Nonspecific antibody binding sites were blocked with $0.5 \%$ nonfat dry milk (5 Prime-3 Prime, Inc., Boulder, $\mathrm{CO}$ ) in $50 \mathrm{~mm}$ Tris buffer containing $45 \mathrm{~mm} \mathrm{NaCl}$ buffer. Blots were incubated overnight with a monoclonal antibody to human neuronspecific enolase (Pierce, Rockford, IL) used at a 1:500 dilution in 50 mм Tris buffer containing $0.5 \%$ dry milk. The blots were rinsed and subjected to further incubation in alkaline phosphatase-conjugated goat anti-mouse $\mathrm{IgG}$ for $2 \mathrm{hr}$ before developing with the alkaline phosphatase color developing reagents $p$-nitro blue tetrazolium chloride (NBT) and 5-bromo-4-chloro-3'-indoyl phosphate $p$-toluidine salt (BCIP).
Table 1. Comparison of rat and human NSE amino acid sequences with those of the $46 \mathrm{kDa}$ protein from bovine IPM

\begin{tabular}{lll} 
& Peptide 1 & Peptide 2 \\
\hline Rat NSE & -PSGASTGIYE-LELR- & -GNPTVEVDLHTAK \\
46 kDa protein & -PSGASTGIYEALELR- & -GNPTVEVDLFTAK- \\
Human NSE & -PSGASTGIYEALELR- & -GNPTVEVDLFTSK-
\end{tabular}

Peptides for the bovine $46 \mathrm{kDa}$ IPM protein were determined as in Materials and Methods and compared with peptide sequences reported for rat and human NSE in GenBank and Sakimura et al. (1985). Italic amino acids indicate differences from the bovine $46 \mathrm{kDa}$ IPM protein.

\section{Trypsin digestion, HPLC separation, and microsequencing}

After electrophoresis by SDS-PAGE, proteins were electrotransferred to nitrocellulose and visualized by staining with Ponceau S (Sigma Chemical Co., St. Louis, MO). The area on the nitrocellulose containing the discrete $46 \mathrm{kDa}$ protein was isolated and subjected to in situ digestion with trypsin (Aebersold et al., 1987), omitting the $\mathrm{NaOH}$ wash. The resulting peptide mixture was separated by narrow-bore, high-performance liquid chromatography (HPLC) using a Vydac $\mathrm{C} 18$ reverse-phase column $(2.1 \times 150 \mathrm{~mm})$ on a Hewlett-Packard 1090 HPLC with a 1040 diode array detector. Optimum fractions from this chromatogram were chosen based on differential UV absorbance at 210,277 , and $292 \mathrm{~nm}$, peak symmetry and resolution. Selected fractions were subjected to automated Edman degradation on an Applied Biosystems 477A protein sequencer. Details of strategies for the selection of peptide fractions and their microsequencing have been previously described (Lane et al., 1989).

\section{NSE immunofluorescence}

Sections of adult bovine retina or preparations of isolated aqueousinsoluble IPM were incubated with $1 \mathrm{mg} / \mathrm{ml}$ of bovine serum albumin (BSA) in $0.1 \mathrm{M}$ PBS for $15 \mathrm{~min}$ and then overnight with human NSE antibody diluted $1: 100$ in $0.1 \mathrm{M}$ PBS containing $1 \mathrm{mg} / \mathrm{ml} \mathrm{BSA}$. The specimens were rinsed with $0.1 \mathrm{M}$ PBS, subjected to further incubation in fluorescein-conjugated goat anti-rabbit IgG (1:50 dilution) for $1 \mathrm{hr}$, and rinsed again with PBS. Immunoreactivity was examined by epifluorescence microscopy using an Olympus BHS microscope. As a positive control, a sample of the aqueous-insoluble IPM was also examined after staining with peanut lectin ( $30 \mathrm{~min}$ at room temperature) as previously described (Johnson and Hageman, 1991).

\section{Tissue culture}

Y-79 human retinoblastoma cells were purchased from American Type Tissue Culture Collection (Rockville, MD). General culture conditions were as previously described (Tombran-Tink et al., 1992). Cells were grown in suspension culture in minimal essential medium (MEM) containing 15\% fetal bovine serum (SC-MEM, GIBCO, Grand Island, NY) until use in the following experiments.

Neuronal differentiation assay. Y-79 cells were grown in suspension culture in serum-free minimal essential medium (SF-MEM) alone or with $33 \mathrm{ng} / \mathrm{ml}$ NSE for $5 \mathrm{~d}$, then seeded into attachment culture in dishes coated with poly-D-lysine. The SF-MEM was supplemented (per $\mathrm{ml}$ ) with $5 \mu \mathrm{g}$ insulin, $5 \mu \mathrm{g}$ transferrin, $5 \mathrm{ng}$ sodium selenite, $50 \mathrm{IU}$ penicillin, and $50 \mu \mathrm{g}$ streptomycin. It also contained $1 \mathrm{~mm}$ sodium pyruvate, $10 \mathrm{~mm}$ Hepes buffer, $2 \mathrm{~mm}$ glutamine, and $0.01 \mathrm{~mm}$ nonessential amino acids. Attached cells were maintained in SF-MEM with no addition of NSE. Morphological changes were observed by light microscopy using a Nikon Diaphot TM D inverted microscope using 3-6 individual culture flasks for each condition.

Cell growth studies. Y-79 cells were maintained in suspension culture as follows: (1) SF-MEM alone; (2) serum-containing MEM (SC-MEM) medium alone; (3) SF-MEM supplemented with $5 \%$ aqueous-soluble IPM (IPM); (4) SF-MEM supplemented with $50 \mathrm{ng} / \mathrm{ml}$ NSE. Medium was replaced on the seventh day of culture (3-6 culture dishes for each condition). The cell numbers were counted by an electronic cell counter (Coulter Counter ZM) at 1, 3, 4, 5, 7, 9, 11, and $14 \mathrm{~d}$ postplating.

Growth parameters were calculated according to the equations outlined by Freshney (1989): (1) specific growth rate $(\mu)=(1 / x)(d x / d t)$ $h^{-1}$, where $d x=$ increase in cell mass, $d t=$ time interval, and $x=$ cell mass (i.e., number); (2) doubling time $(\mathrm{td})=\ln 2 / \mu$.

Cell survival assay. Y-79 cells were maintained in suspension culture 


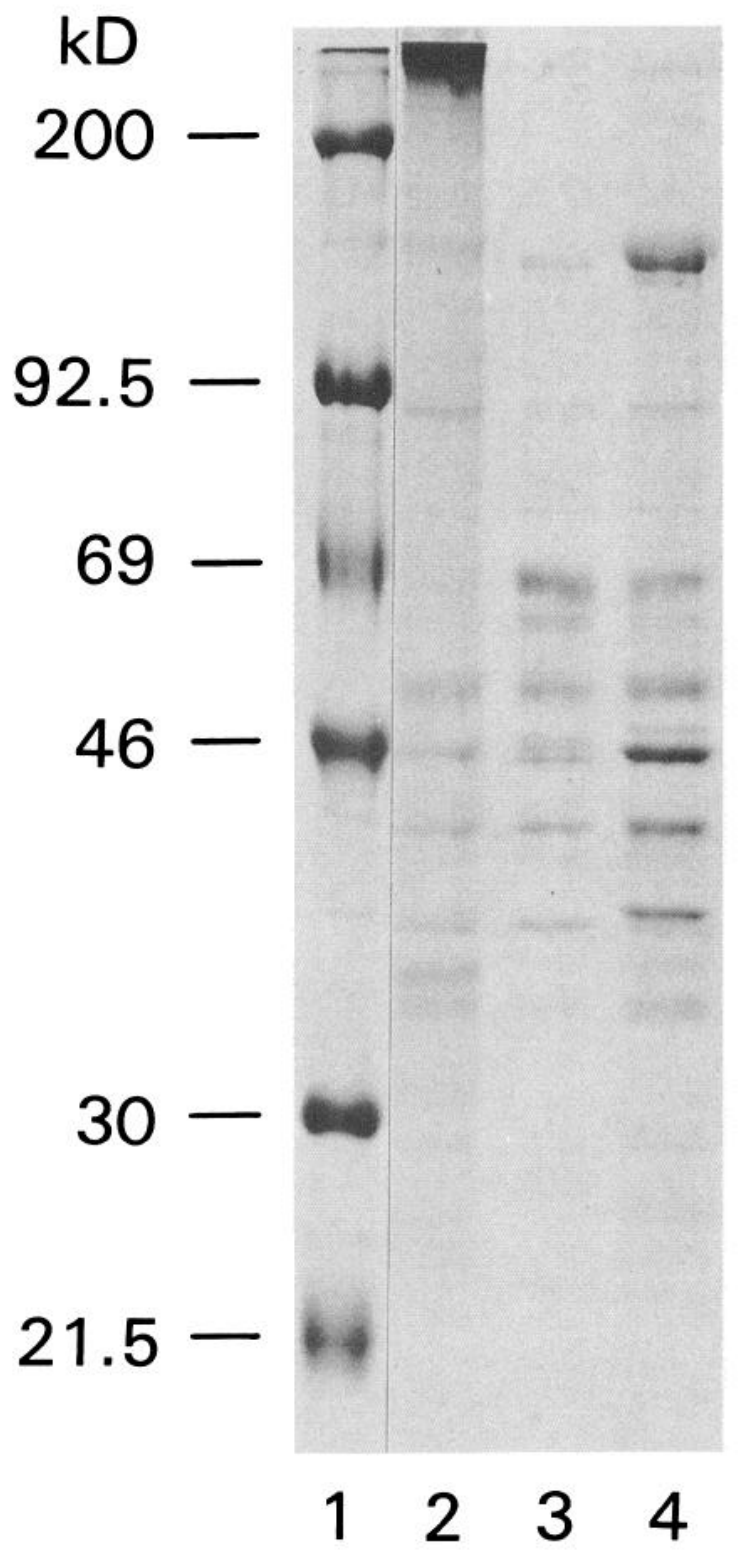

Figure 2. Coomassie blue-stained SDS-PAGE profiles of IPI teins. Lane 1, Molecular weight standards. Lane 2, Aqueous-ins bovine IPM. Lane 3, Soluble proteins of adult human IPM. L Soluble proteins of adult bovine IPM. Forty-six kilodalton bar apparent in all samples.

in SF-MEM alone or supplemented with NSE at $33 \mathrm{ng} / \mathrm{ml}, 50$ or $100 \mathrm{ng} / \mathrm{ml}$; 3-6 individual cultures were used for each con NSE was added once each week without medium change. At tl of 4 weeks, the cells were stained with trypan blue and the perce of surviving cells were determined by counting the cells under verted tissue culture microscope.

\section{Results}

\section{SDS-PAGE and amino acid analysis}

Aqueous-soluble IPM components were separated by electrophoresis on $10 \%$ SDS-polyacrylamide gels (Fig. 1). In the IPM from the adult human eye (Fig. 1, lane 1) a band is seen at about $46 \mathrm{kDa}$, while an intense single $46 \mathrm{kDa}$ band is observed in adult bovine IPM (Fig. 1, lane 2). Purified NSE runs in an identical position under these conditions (Fig. 1, lane 4). Isolated aqueous-insoluble IPM (containing photoreceptor sheaths) also

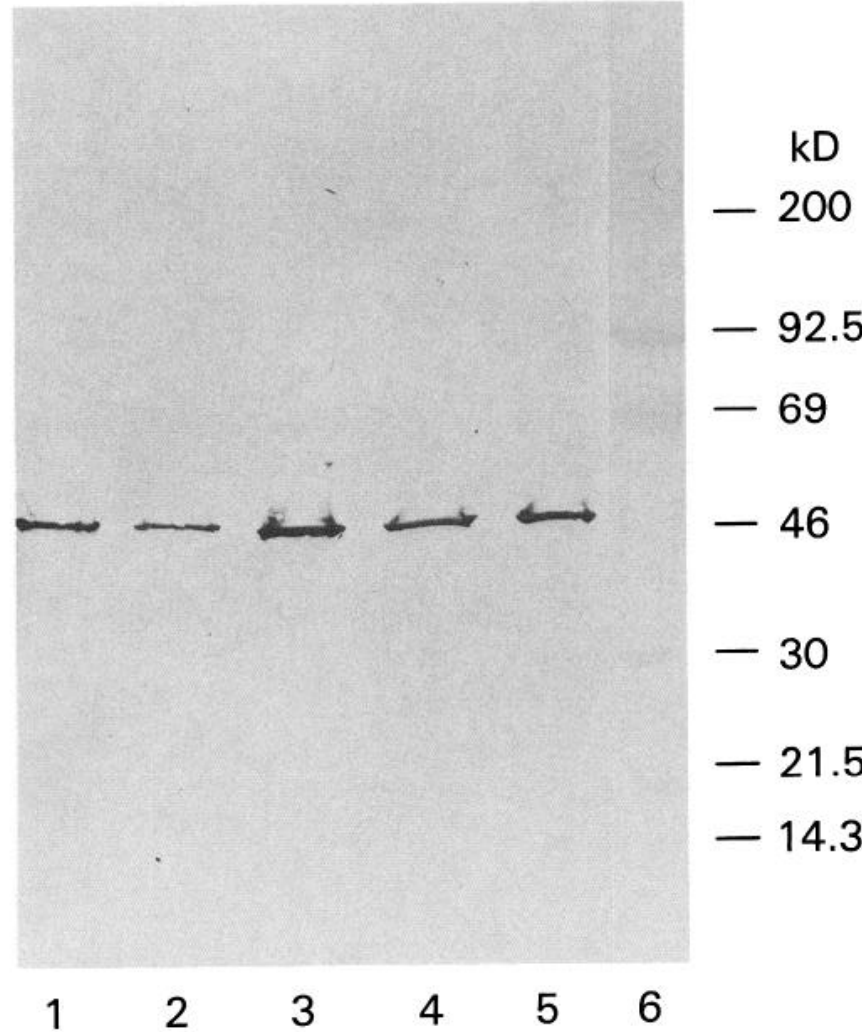

Figure 3. Western blot analysis of IPM proteins using a human NSE antibody. Lane 1, Purified human NSE. Lane 2, Aqueous-insoluble bovine IPM. Lane 3, Soluble proteins of adult human IPM. Lane 4, Soluble proteins of adult bovine IPM. Lane 5, Soluble fraction $(10,000$ $\times g$ supernatant) of adult bovine retina. Lane 6 , Indicated position of molecular weight standards. The samples were separated on 3-15\% SDS gradient polyacrylamide gel. A $46 \mathrm{kDa}$ band is detected by the monoclonal antibody to human NSE in all the samples.

demonstrates a $46 \mathrm{kDa}$ band (Fig. 2, lane 2) that is comparable in mobility to the doublet in adult human IPM (Fig. 2, lane 3) and the band in adult bovine IPM (Fig. 2, lane 4).

The $46 \mathrm{kDa}$ band in the soluble bovine IPM extract was of particular interest since it was so prominent and close to the size known for human PEDF. Using Edman microsequencing, two peptide sequences were obtained from this protein, as given in Table 1. Comparison of these peptides with those reported in GenBank and Sakimura et al. (1985) revealed that both share close homology to sequences found in rat and human NSE. These results strongly suggest that the $46 \mathrm{kDa}$ protein band of bovine IPM is NSE or a close cognate.

\section{Western blot analysis}

In order to further test for the existence of NSE in IPM, Western blots were performed using a monoclonal antibody to human NSE. As expected, the antibody recognized authentic, purified NSE demonstrating a single band at about $46 \mathrm{kDa}$ (Fig. 3, lane 1). A single band of identical size was also recognized by the human anti-NSE in the aqueous-insoluble fraction of IPM (Fig. 3 , lane 2) as well as in the soluble fractions of adult human (Fig. 3, lane 3) and bovine (Fig. 3, lane 4) IPM preparations. The 46 $\mathrm{kDa}$ band is also apparent in soluble extracts of bovine retina (Fig. 3, lane 5). This could be due to the actual presence of intracellular NSE in the retina and/or due to adventitious adhesion of IPM components to the retinal surface. These im- 


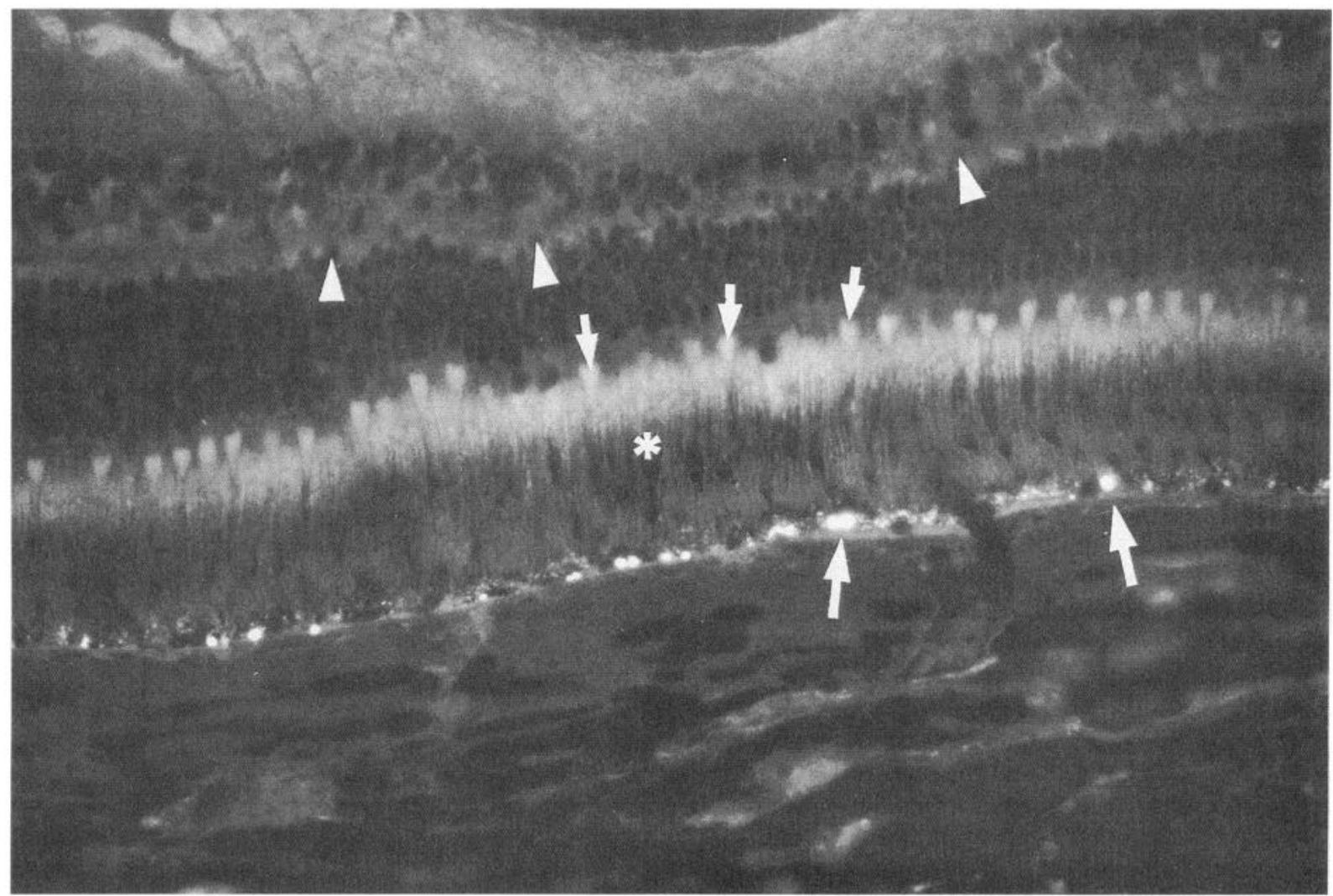

Figure 4. Immunocytochemical analysis of adult bovine retina using a human NSE antibody. The micrograph indicates high immunoreactivity of anti-NSE in the basal domain of the IPM (below the asterisk) and the cone photoreceptor inner segments (short arrows). Immunoreactivity is also seen in the rod inner segments and in the ganglion cell layer (arrowheads). The yellow band composed of discontinuous globular-like bodies below the IPM is autofluorescence in the retinal pigment epithelium $(1250 \times)$.

munological results, however, are compatible with the possibility that NSE is a component of gentle IPM washes and of purified aqueous-insoluble photoreceptor matrix.

\section{Immunofluorescence analysis}

To further explore the presence of NSE in the retina and IPM, sections of adult bovine retina were stained with monoclonal antibody to human NSE. As seen in Figure 4, immunofluorescence is mainly associated with the photoreceptor area; the inner segments of cones are intensely stained as well as staining in the rod inner segments. The basal extracellular matrix region surrounding rod and cone inner segments is also intensely stained. We also investigated NSE staining of the isolated sheets of aqueous-insoluble IPM that contain the photoreceptor matrix sheaths (Figs. 5, 6). Figure 5 shows the highly structured architecture of the sheets as elucidated by staining with peanut lectin (PNA). As previously described by Johnson and Hageman (1991), intense staining is seen in a tight ring around the apertures (sheaths) through which the large cone outer segments penetrate in vivo (Fig. 5A). The areas in between the cone sheaths are also composed of aqueous-insoluble IPM and mainly correspond to the domains of the smaller rod outer segments (small, honeycomb areas in Fig. 5A). These areas stain much less intensely with PNA. The more oblique section shown in Figure $5 B$ illustrates the three-dimensional structure of the cone sheaths stained with PNA. Figure 6 compares PNA and NSE immunofluorescent staining. Figure $6 A-C$ shows views of cone domains stained with PNA, while $D-F$ shows views of the matrix material stained with NSE. It is clear that NSE staining is more widespread through the insoluble matrix material and is not limited to the area of the cone matrix sheath defined by PNA. Figure $6 G$ shows a negative control where specific NSE antibody was omitted.

Studies on differentiation, cell growth, and survival

The effects of NSE on the differentiation, proliferation, and longevity of Y-79 human retinoblastoma cells in tissue culture were investigated.

Neuronal differentiation. Y-79 retinoblastoma cells were grown in suspension culture in serum-free medium alone or SF-MEM supplemented with NSE for $5 \mathrm{~d}$, then seeded onto poly-D-lysine (PDL)-coated culture plates for attachment culture. The morphology of attached cells was observed after $3 \mathrm{~d}$ of attachment. All cells remained morphologically undifferentiated and undistinguished in both suspension culture (data not shown) and attachment culture (Fig. 7). No morphological differences were found between the NSE-treated cultures (Fig. 7A) and the control, nontreated cultures (Fig. 7B). Other control experiments show that the Y-79 cells do have the potential for marked neuronal differentiation when treated under the same conditions with a crude soluble extract of IPM (Tombran-Tink et al., 1992) or with purified PEDF (Tombran-Tink et al., 1991; Steele et al., 1993).

Cell growth. Figure 8 shows the growth curves of Y-79 retinoblastoma cells under four different conditions in suspension culture for 2 weeks. Table 2 shows the growth parameters of Y-79 retinoblastoma cells determined from the relevant growth 

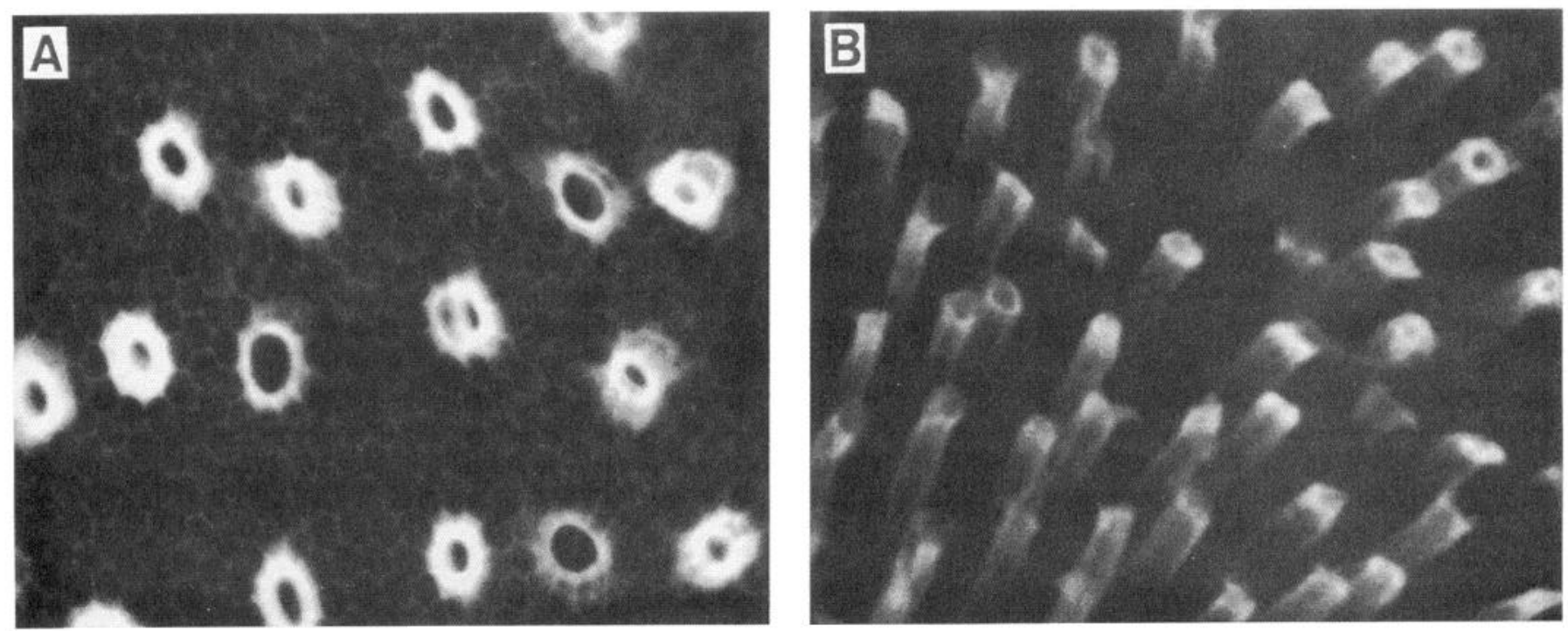

Figure 5. Peanut lectin (PNA) staining illustrating the different domains in isolated, aqueous-insoluble sheets of IPM. $A$, Larger cone sheaths are intensely stained by PNA, while the smaller honeycomb pattern of IPM material surrounding the rod sheaths is poorly stained ( $250 \times)$. $B$, Oblique view of cone sheaths $(400 \times)$.

curves. The growth cycle of cells is conventionally divided into three phases: the lag phase, the log growth phase, and the plateau phase. As seen in Figure 8, the length of the lag phase of the cells treated with NSE is approximately $72 \mathrm{hr}$, a value similar to that for cells grown in serum-free medium (SF-MEM) alone. This is $2-3$ times longer than that for cells grown in serumcontaining medium (SC-MEM) or those treated with IPM (24 $\mathrm{hr}$ ). The population-doubling time of the cells treated with NSE is about $48 \mathrm{hr}$. This is considerably shorter than that of the SFMEM group ( $74 \mathrm{hr}$ ) but similar to those of cultures containing serum (SC-MEM) or those supplemented with IPM. The calculated growth rate of the NSE group (0.014) thus was higher than that of the SF-MEM group (0.009) and close to the SCMEM and IPM groups (0.015). As expected, cells grown in serum-containing medium demonstrated the highest saturation density, cells grown in serum-free medium the lowest, and cells treated with NSE or IPM were intermediate. The results suggest that NSE in nanogram amounts has effects on both growth and proliferation of Y-79 retinoblastoma cells.

Cell survival effect. The number of living Y-79 cells in suspension culture in SF-MEM was determined with or without the addition of NSE. NSE was added every week but without changing the medium. The culture was continued for 4 weeks, and the surviving cells were counted under the inverted phasecontrast microscope. Morphologically, the vital, undifferentiated Y-79 retinoblastoma cell is small, round, and refractile with scant cytoplasm and a large nucleus. The unhealthy cells appear granular and display vacuolation around the nucleus. Dead cells become wrinkled and the nucleus is not clearly resolved. Most obviously, they become trypan blue positive. When the Y-79 cells were cultured at a high cell density, that is, $1 \times 10^{7}$ cells/ $\mathrm{ml}$, most of the cells grown in serum-free medium died within 1 week, but virtually all of the cells cultured with $50 \mathrm{ng} / \mathrm{ml} \mathrm{NSE}$ remained alive. When the cells were cultured with NSE at a lower cell density, $1 \times 10^{5}$ cells $/ \mathrm{ml}$, for a 4 week period, the situation was similar in that many more NSE-treated cells remained trypan blue negative than those in control cultures (Fig. 9). Treatment with 33,50 , and $100 \mathrm{ng} / \mathrm{ml}$ of NSE resulted in 24,28 , and $26 \%$ of the cells surviving in the respective cultures. In comparison, only $4 \%$ of the cells survived when grown in serum-free medium not supplemented with NSE (Fig. 10). Using the $\chi^{2}$ test, the difference between the percentage of cells surviving under control conditions versus those treated with NSE was significant $(p<0.01)$. There were no significant differences seen between the three different concentrations of NSE used.

\section{Discussion}

In recent years, many studies have focused on the structure, composition, and function of molecules within the extracellular matrix in different tissues. The retinal interphotoreceptor matrix (IPM) can be used as a model for studies of such matrices in neuronal tissues since it is readily accessible and is a closed compartment bordered by well defined cell types: pigment epithelial cells, retinal glial (Muller) cells, and photoreceptor (rod

\section{Table 2. Growth parameters of Y-79 retinoblastoma cells}

\begin{tabular}{lllll} 
Parameter & NSE & SF-MEM & SC-MEM & IPM \\
\hline Lag period $(\mathrm{hr})$ & 72 & 72 & 72 & 24 \\
Doubling time $(\mathrm{hr})$ & 48 & 74 & 46 & 46 \\
Growth rate $(\mu)$ & 0.014 & 0.009 & 0.015 & 0.015 \\
Saturation density $\left(\times 10^{-5}\right)$ & $7.4 \pm 0.3$ & $4.5 \pm 0.4$ & $10.0 \pm 1.7$ & $8.8 \pm 0.2$
\end{tabular}

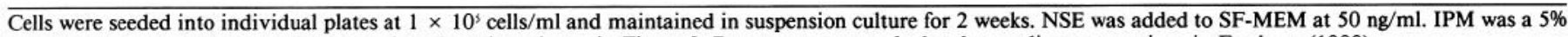
addition to SF-MEM. Calculations were based on data shown in Figure 8. Parameters were calculated according to equations in Freshney (1989). 
$390 \mathrm{Li}$ et al. - NSE in the Interphotoreceptor Matrix
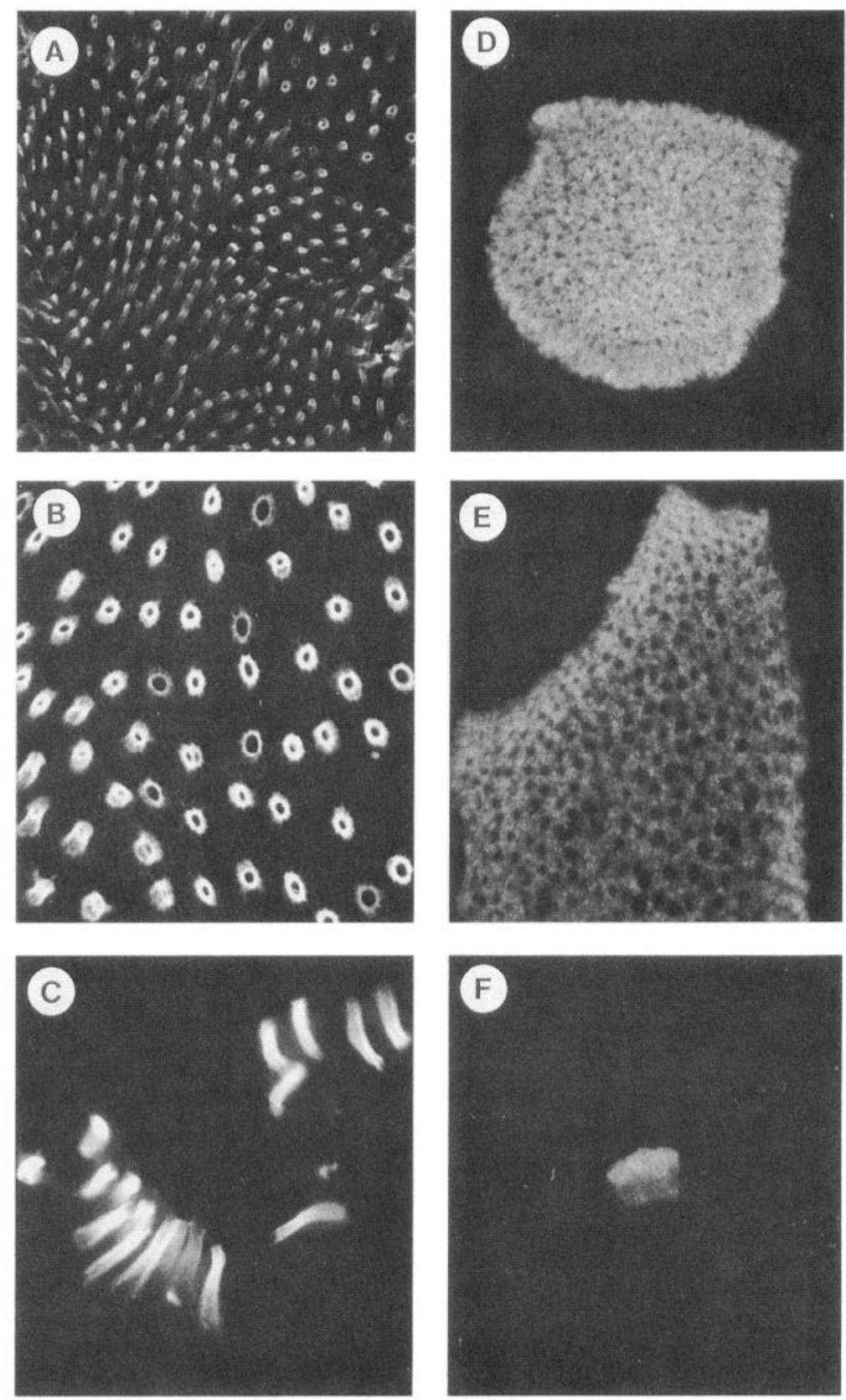

Figure 6. PNA and NSE staining in isolated sheets of aqueous-insoluble IPM. $A-C$, PNA staining concentrated in the cone sheath areas. The intensely stained regions correspond to IPM domains surrounding cone cell outer segments. Darker surrounding areas mainly represent rod outer segment domains within the IPM. $D-F$, NSE staining is observed more diffusely throughout the insoluble matrix. There is no preferential compartmentalization to either rod or cone domains, although the immediate areas around the cone apertures are not stained. $G$, Negative control where only second antibody (GARFITC) was applied. $A$ and $D, 50 \times ; B$, $C$, and $E-G, 100 \times$.

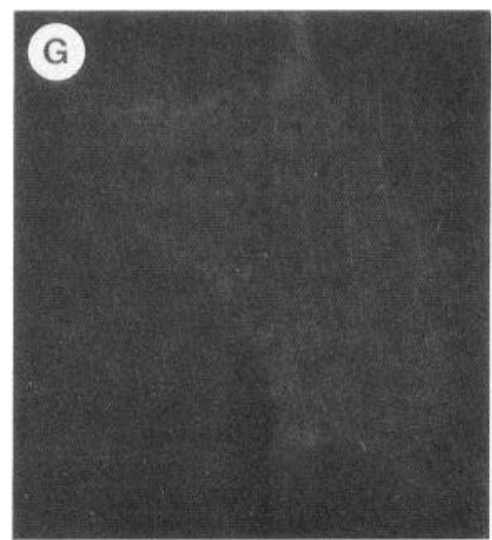



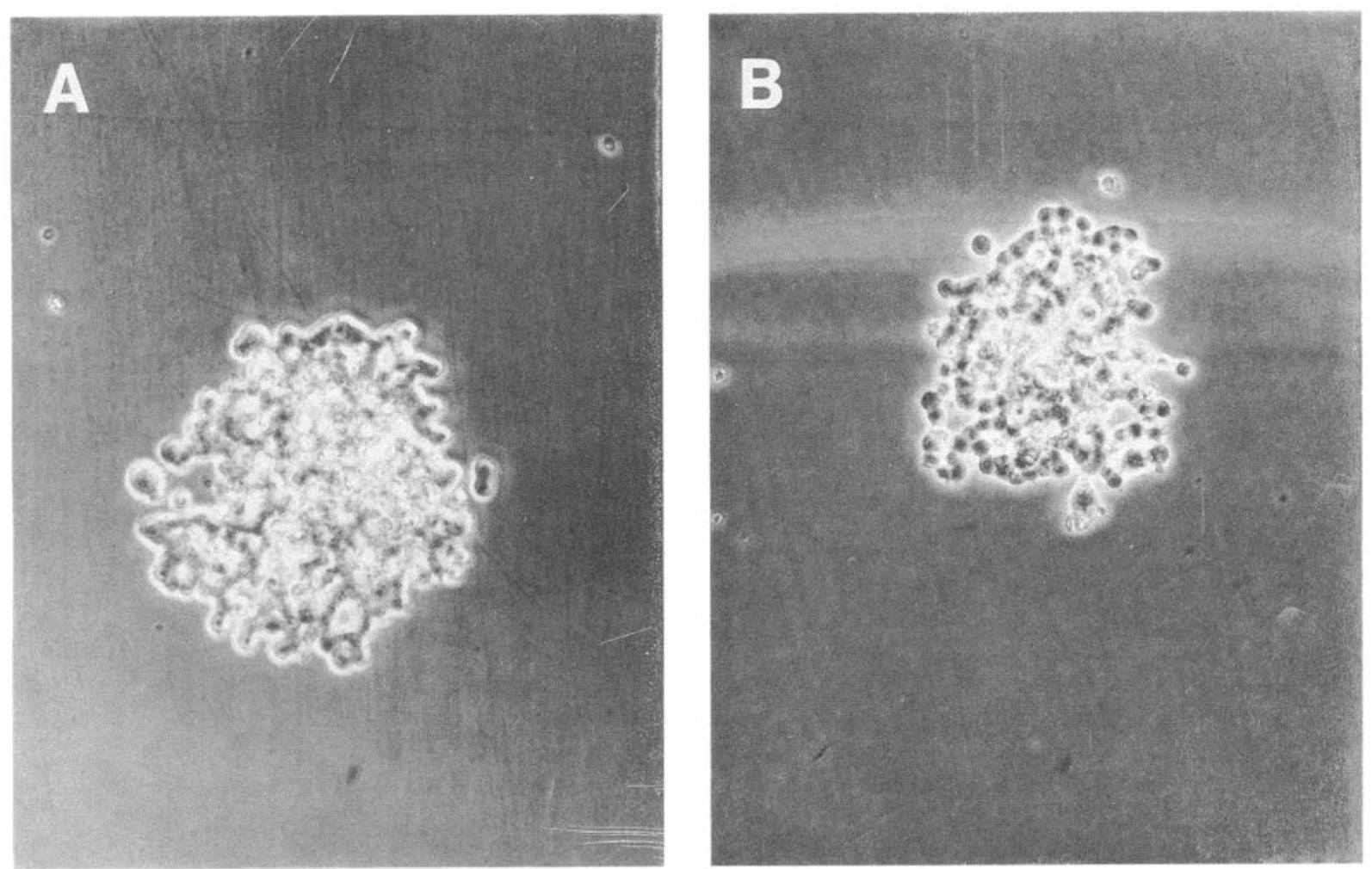

Figure 7. Lack of neurotrophic activity of NSE. Y-79 retinoblastoma cells were maintained in suspension culture in SF-MEM for 5 d with $(A)$ no supplement or $(B)$ addition of $33 \mathrm{ng} / \mathrm{ml}$ NSE. The cells were then plated in attachment culture at a density of $1 \times 10^{6}$ cells $/ \mathrm{ml}$ using SF-MEM. After $3 \mathrm{~d}$, morphology was examined. No morphological differences were observed between cells treated and not treated with NSE $(168 \times)$.

and cone) neurons. New studies have demonstrated that the IPM is not of homogenous composition but contains highly structured domains (Hageman and Johnson, 1991). To date, only one IPM component has been well characterized, the interphotoreceptor retinol-binding protein (IRBP) (Chader, 1989); most remain poorly understood in both nature and function.

In the present study, we focused our attention on the limited number of readily soluble components of the IPM, in particular the prominent $46 \mathrm{kDa}$ protein observed in the bovine IPM (see Fig. 1). This protein was of special interest because of the previous discovery of a protein (PEDF) of similar size that is secreted by fetal human retinal pigment epithelial cells. PEDF is a protein of about $50 \mathrm{kDa}$ that demonstrates potent neurotrophic activity in the Y-79 retinoblastoma culture system (TombranTink et al., 1991) and belongs to the SERPIN supergene family (Steele et al., 1993). Moreover, it has also been shown that adult bovine IPM contains potent neurotrophic activity (TombranTink et al., 1992) with many of the characteristics exhibited by PEDF. We were thus surprised when the peptide sequence analysis of the two peptides isolated from the $46 \mathrm{kDa}$ bovine protein showed no homology to PEDF but rather was virtually identical to sequences within human and rat NSE. Western blotting using a monoclonal antibody to human NSE recognized the $46 \mathrm{kDa}$ protein in both adult bovine and human IPM preparations. Since the retinas are easily and cleanly removed from the eye cups prior to the gentle IPM washing procedure, it would seem unlikely that the observed NSE is simply present in the washes due to tissue damage, particularly since it is one of the major components of the IPM, as seen in Figure 1. Moreover, NSE is also found in more stringently isolated bovine aqueous-insol- uble IPM structures, again indicating that the NSE is not a loosely bound contaminant in the IPM but perhaps an integral component of the matrix. Importantly, immunocytochemical studies demonstrate that NSE is present in a pattern different

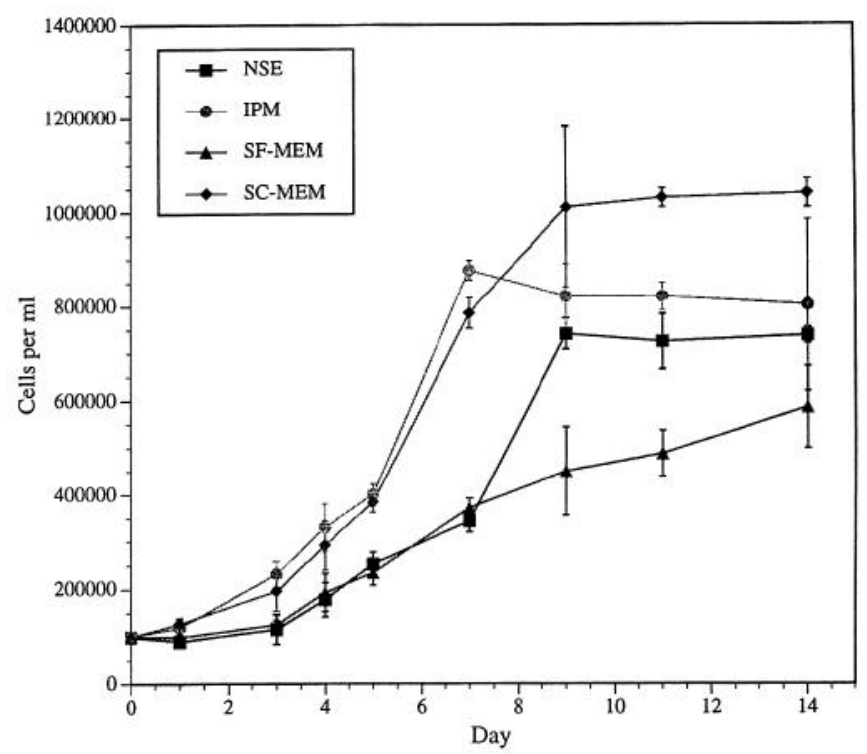

Figure 8. Growth curve of Y-79 retinoblastoma cells in suspension culture. $S C-M E M$, Serum-containing medium (15\% FBS); $S F-M E M$, serum-free medium; IPM, serum-free medium supplemented with $5 \%$ IPM; NSE, serum-free medium supplemented with $50 \mathrm{ng} / \mathrm{ml} \mathrm{NSE}$. Values given $( \pm S D)$ are means of triplicate cultures in three separate experiments. 

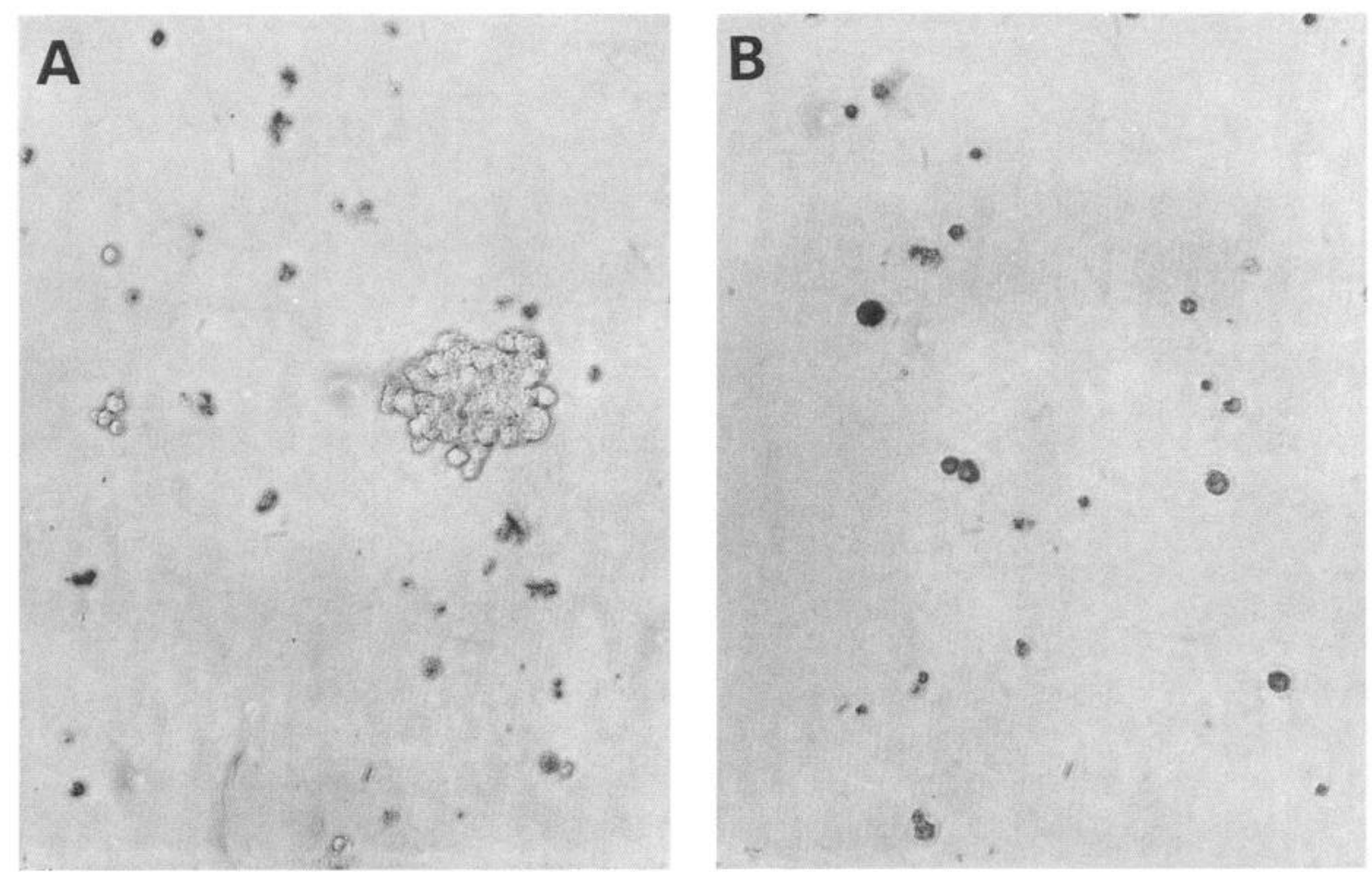

Figure 9. Trypan blue staining of typical Y-79 retinoblastoma cells after 4 weeks in suspension culture maintained in SF-MEM with $(A)$ or without (B) $50 \mathrm{ng} / \mathrm{ml}$ NSE. The seeding density in both cases was $1 \times 10^{5}$ cells $/ \mathrm{ml}$. More viable cells remain with NSE treatment $(168 \times)$.

from that seen with peanut agglutinin (PNA), which binds only to elements of cone matrix sheaths (Hageman and Johnson, 1991). Together, these results thus suggest that NSE is a bone fide component of the mammalian IPM. Based on the analysis of the two peptides we have studied, we cannot rule out the possibility that the bovine $46 \mathrm{kDa}$ protein is not NSE but a closely homologous protein, perhaps in the same gene family. Most probably, though, the amino acid differences observed

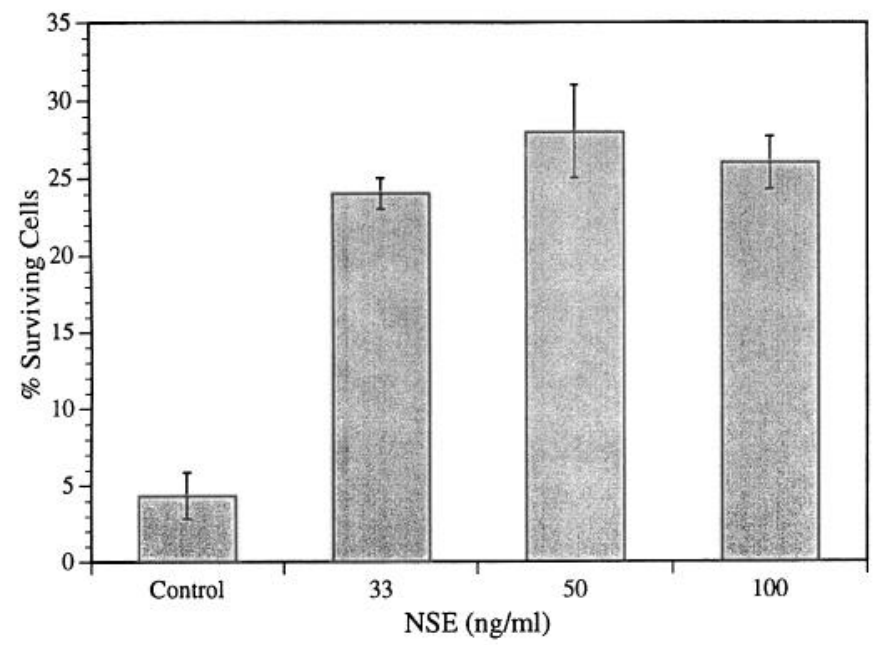

Figure 10. The percentage of surviving Y-79 cells after 4 weeks in suspension culture incubated in SF-MEM (control) or in SF-MEM containing three different concentrations of purified human NSE. The original seeding density in all cases was $1 \times 10^{5}$ cells/ml. Values given $( \pm$ $\mathrm{SD})$ are means of triplicate cultures from three separate experiments. between the sequences of the bovine IPM protein and the human and rat NSE sequences are due to species variation. Interestingly, cDNA analysis of the NSE protein to date indicates that it does not contain the usual leader sequence thought to facilitate the extracellular secretion of proteins (Sakimura et al., 1985). Hayashi et al. (1987), however, did report the extracellular presence of NSE in some tumor tissues as well as within the tumor cells themselves. Our study now gives strong evidence for the localization of NSE in at least one extracellular matrix: the IPM of the neural retina under normal conditions.

As one of the classical enzymes in the glycolytic pathway, enolase is usually considered to be a soluble cytoplasmic protein. The enzyme is dimeric with three types of isozymes: $\alpha \alpha, \beta \beta$, and $\gamma \gamma$, each encoded by different genes (Schmechel et al., 1980; Marangos, 1987). Only the $\gamma \gamma$ enolase form is present at a high level in brain and at intermediate levels in peripheral nervous tissue and various neuroendocrine glands, such that it is considered to be a specific marker for neurons, neuroendocrine cells, and their derived tumors (Hayashi et al., 1987; Marangos, 1987). Interestingly, it can account for up to $1.5 \%$ of total protein in some neurons and thus may have functions other than enzymic (Schmechel et al., 1980). In normal human retina and retinoblastoma tumor, NSE has been detected by biochemical and immunohistochemical methods, although the results vary depending on the type of specimen and the methodology (Molnar et al., 1984; Kivela, 1986). Molnar et al. (1984), for example, reported that an antiserum against NSE stained perikarya and processes of neurons in all layers of the human retina. Kivela (1986) reported that both outer and inner segments of retinal photoreceptor cells as well as their cell bodies and axons showed positive staining with a polyclonal antiserum against NSE. In the present study using a monoclonal antibody to human NSE, 
we found intraccllular immunostaining to be most prominent in the inner segments of cone photoreceptors, perhaps indicating an important cytoplasmic role for the protein/enzyme within these highly specialized neurons.

Along with its enzymatic role in glycolysis, some evidence indicates that NSE can act as a neuronal survival factor in the central nervous system. Takei et al. (1991) found that NSE significantly promotes survival of embryonic rat neocortical neurons in primary culture over a 4-6 d period. Due to the difficulties involved in growing primary cultures of retinal neurons, especially photoreceptors, cultured retinoblastoma cells are often used as a model system (Campbell and Chader, 1988; Tombran-Tink and Johnson, 1989). We have especially used the human Y-79 cell line since it appears to have a cone photoreceptor cell lineage (Bogenmann et al., 1988). It also exhibits multipotential differentiative ability in culture (Kyritsis et al., 1984), spccifically responding to the addition of agents such as cAMP and PEDF by extending a complex meshwork of neuritic processes (Kyritsis et al., 1984; Tombran-Tink et al., 1991). Treatment of Y-79 cells with purified NSE in tissue culture, however, did not elicit a neurotrophic phenotypic response. We did find, though, that NSE possesses cell growth and/or neuronal survival (neuronotrophic) activity for the cultured human retinoblasts. When the cells were treated with NSE in suspension culture, the population-doubling time was decreased and the apparent growth rate was increased compared to the control group cultured in SF-MEM alone. Most striking, the survival rate of the cells treated with NSE was 6-7 times greater than those in the control group after 4 weeks of culture. In these experiments, we specifically chose to culture the Y-79 cells under relatively adverse conditions, that is, serum-free conditions with no medium changes for the 4 week test period. We thus feel that the effects of NSE were more to "rescue" the cells rather than to increase cell division, as seen with the results of the trypan blue staining. Future studies will be needed to better clarify this point, however.

Although the neuronotrophic mechanism of action of NSE is unknown, our results and those of Takei et al. (1991) demonstrate that NSE has a potent effect in promoting the growth and/ or survival of two cell types derived from different areas of the CNS. Intriguingly, NSE seems to be present in relatively high concentrations in the adult IPM surrounding the photoreceptor elements and in inner segments of cone neurons, the normal counterpart of the cultured Y-79 cell. Thus, along with effects in early growth and development, it will be interesting to explore the possible role(s) of NSE in neuron longevity, neuropathology, and transplantation studies in the retina and other parts of the CNS.

\section{References}

Adler AJ, Klucznik KM (1982) Proteins and glycoproteins of the bovine interphotoreceptor matrix: composition and fractionation. Exp Eye Res 34:423-434.
Aebersold RH, Leavillt J, Saavedra RA, Hood LE, Kent SB (1987) Internal amino acid sequence analysis of proteins separated by one or two-dimcnsional gel electrophoresis after in situ protease digestion on nitrocellulose. Proc Natl Acad Sci USA 84:6970-6974.

Bogenmann E, Lochrie MA, Simon MI (1988) Cone cell-specific genes expressed in retinoblastoma. Science 240:76-78.

Campbell MA, Chader GJ (1988) Retinoblastoma cells in tissue culture. Ophthalmic Paediatr Genet 9:171-199.

Chader GJ (1989) Interphotoreceptor retinoid-binding protein (IRBP): a model protein for molecular biological and clinically-relevant studies. Invest Ophthalmol Vis Sci 30:7-22.

Freshney RI (1989) Animal cell culture: a practical approach, pp 3738. Oxford: IRL.

Hageman GS, Johnson LV (1991) Structure, composition and function of the retinal interphotoreceptor matrix. Prog Ret Res 10:207-249.

Hayashi KM, Motoi Y, Horie K, Ogawa K, Taguchi K, Mizobuchi N, Nishimoto A (1987) An immunohistochemical study on the distribution of glial fibrillary acidic protein, $s-100$, neuron-specific enolase and neurofilament in medulloblastomas. Acta Pathol Jpn 37:85-96.

Johnson LV, Hageman GS (1991) Structural and compositional analyses of isolated cone matrix sheaths. Invest Ophthalmol Vis Sci 32: 1951-1957.

Kivela T (1986) Neuron-specific enolase in retinoblastoma. An immunohistochemical study. Acta Ophthalmol 64:16-25.

Kyritsis AP, Tsokos M, Triche T, Chader GJ (1984) Retinoblastomaorigin from a primitive neuroectodermal cell? Nature 307:471-473.

Lane WS, Galat A, Harding MW, Schreiber SL (1991) Complete amino acid sequence of the FK506 and rapamycin binding protein, FKBP, isolated from calf thymus. J Protein Chem 10:151-160.

Marangos PJ (1987) Neuron specific enolase, a clinically useful marker for neurons and neuroendocrine cells. Annu Rev Neurosci 10:269295.

Martin GR, Timpl R (1987) Laminin and other basement membrane components. Annu Rev Cell Biol 3:57-85.

Molnar ML, Stefanson K, Marton LS, Tripathi RS, Molnar GK (1984) Immunohistochemistry of retinoblastoma in humans. Am J Ophthalmol 93:301-307.

Sakimura KE, Kushiya M, Obinata S, Odani S, Takahashi Y (1985) Molecular cloning and the nucleotide sequence of cDNA for neuronspecific enolase messenger RNA of rat brain. Proc Natl Acad Sci USA 82:7453-7457.

Schmechel DE, Brightman MW, Marangos PJ (1980) Neurons switch from non-neuronal enolase to neuron-specific enolase during differentiation. Brain Res 190:195-214.

Steele FR, Chader GJ, Johnson LV, Tombran-Tink JA (1993) Pigment epithelium-derived factor: neurotrophic activity and identification as a member of the serine protease inhibitor gene family. Proc Natl Acad Sci USA 90:1526-1530.

Takei NJ, Kondo K, Nagaike K, Ohsawa K, Kato K, Kohsaka S (1991) Neuronal survival factor from bovine brain is identical to neuronspecific enolase. J Neurochem 57:1178-1184.

Tombran-Tink JA, Johnson LV (1989) Neuronal differentiation of retinoblastoma cells induced by medium conditioned by human RPE cells. Invest Ophthalmol Vis Sci 30:1700-1707.

Tombran-Tink JA, Chader GJ, Johnson LV (1991) PEDF: a pigment epithelium-derived factor with potent neuronal differentiative activity. Exp Eye Res 53:411-414.

Tombran-Tink JA, Li A, Johnson MA, Johnson LV, Chader GJ (1992) Neurotrophic activity of the interphotoreceptor matrix on human Y79 retinoblastoma cells. J Comp Neurol 317:175-186. 